\title{
Consideraciones sobre la
}

separación del cargo por

incumplimiento de la

responsabilidad y desempeño

de sus funciones de acuerdo a

la reforma constitucional penal en México de 2008* /

Considerations on the

separation from the charge

regarding breach of

responsibility and performance

of duties according to the

criminal constitutional reform

in mexico 2008

* Recibido: 9 de enero de 2012. Aceptado: 11 de febrero de 2012.

Tla-Melaua, Revista de Ciencias Sociales. Facultad de Derecho y Ciencias Sociales. Benemérita Universidad Autónoma de Puebla, México / isss: 1870-6916 / Nueva Época, Año 6 N 32, Abril - Septiembre 2012, pP. 110-137. 
La Reforma Constitucional Penal en México de 2008 se ha considerado como trascendente, entre otras razones, porque se modificó el contenido de 10 artículos de la Constitución, a saber: 16, 17, 18, 19, 20, 21, 22, 73, fracciones XXI, y XXIII, 115 fracción VII y fracción XIII del apartado в del artículo 123.

Sin embargo, la separación del cargo por incumplimiento de la responsabilidad y desempeño de sus funciones en relación a la fracción XIII del apartado в del artículo 123 constitucional, cuando ésta no es probada, resulta una injusticia que trastoca la epistemología garantista por intolerante y autoritaria. Dicho supuesto es por demás violatorio de los derechos fundamentales y de las garantías individuales que consagra nuestra Carta Magna, a partir de la reforma del 10 de junio de 2011.

\section{PALABRAS CLAVE}

Separación, incumplimiento, responsabilidad, funciones, garantismo.
The Mexican criminal constitutional reform in 2008 has been seen as transcendent, among others reasons because it modify the content of 10 articles of the existing Political Constitution of the Mexican United States, namely: 16, 17, 18, 19, 20, 21, 22, 73 fractions XXI and XXIII, 115 VII fraction and fraction XIII of part B of article 123.

However, removal from office for breach of responsibility and performance of their duties in relation to fraction XIII part B of article 123 of the Constitution, when this is not proven it is an injustice that upsets the epistemology of the guarantees by intolerant and authoritarian. This issue is another violation of fundamental rights and individual guarantees enshrined in our Constitution, since the reform of June 10, 2011.

\section{KEYWORDS}

Separation, breach, responsibility, functions, guarantor.

\footnotetext{
** Profesor-investigador en la Facultad de Derecho y Ciencias Sociales de la Benemérita Universidad Autónoma de Puebla, México. (rsva7@hotmail.com)
} 
I. Introducción

II. Breves Reflexiones sobre los males que aquejan a los servidores públicos en México

III. Descripción y análisis jurídico sobre la separación del cargo por incumplimiento de la responsabilidad en el desempeño de sus funciones

IV. Algunas tesis sobre la responsabilidad en el desempeño de la función pública emitidas por el Poder Judicial de la Federación

v. Consideraciones Finales

vi. Bibliografía

En una sociedad democrática es imposible mantener la visión positivista (exegética) según la cual el derecho no es otra cosa que la expresión arbitraria de la voluntad del soberano. Para funcionar eficazmente, el derecho debe ser aceptado y no sólo impuesto por medio de la coacción.

Chain Perelman ${ }^{1}$

\section{I . INTRODUCC I ÓN}

Existe una opinión pública generalizada de falta de confianza y credibilidad acerca de los servidores públicos que participan en la procuración e impartición de justicia. Así como de quienes coadyuvan en la seguridad pública, entre otras razones, por su falta de eficacia, eficiencia, imparcialidad, objetividad, transparencia, etc.

Resulta un clamor popular la necesidad de transformar radicalmente todo el proceso penal en México para dejar atrás su naturaleza inquisitoria, donde la carga de la prueba queda en manos del acusado y el Ministerio Público (órgano de procuración de justicia dependiente del Ejecutivo) juega el papel de parte e investigador de los delitos simultáneamente. ${ }^{2}$

La Reforma Constitucional Penal del 18 de junio de 2008, implica una serie de cambios paradigmáticos que permiten transitar, por una parte, de una cultura jurídica eminentemente exegética caracterizada por el excesivo formalismo que obstaculiza y entorpece la procuración, administración e impartición de justicia, y por la otra, hacia una cultura sustentada en el

\footnotetext{
${ }^{1}$ Perelman, Ch.; La lógica jurídica y la nueva retórica, trad. al español por Luis Díez-Picazo. Ed. Civitas, Madrid, 1979, p. 231.

${ }^{2}$ Concha Cantú, Hugo Alejandro y José Antonio Caballero Juárez: Diagnóstico sobre la administración de justicia en las entidades federativas. Un estudio institucional sobre la justicia local en México; $1^{\text {a }}$ ed. Ed. Instituto de Investigaciones de Jurídicas de la UnAM, México, D.F. 2001, pp. 317 y 322.
} 
realismo jurídico que se distingue por ser más racional y pragmática, a fin de lograr una mayor eficacia y eficiencia tanto en la procuración, administración como en la impartición de la justicia penal.

Ahora bien, con el propósito de precisar aun más el sentido y alcance de lo que encierra la cultura jurídica exegética. A continuación hacemos referencia de las siguientes reflexiones. Así pues, para el Jurista y Politólogo Marcos Kaplan, considera:

Los juristas para el siglo Xxi no pueden aceptar el derecho como instrumento de opresión, conformismo ni evasión. No pueden reducirse a la mera exégesis y manipulación de textos, ni a la aplicación de códigos y leyes como algo dado para siempre, realidad rígida e inmutable. Deben huir de la abstracción gratuita, del formalismo, de la pura especulación, de la falsa sutileza. Deben evitar el ritualismo y la jerga, preocuparse por la simplicidad, la racionalidad, el realismo, la respuesta creativa ante conflictos, dilemas nuevas situaciones y desafios. ${ }^{3}$

Ahora bien, con la Reforma Constitucional antes mencionada, se pretende a través del realismo ${ }^{4}$ jurídico lograr una nueva cultura jurídica en México, que permita a los justiciables una mayor eficacia y eficiencia tanto en la procuración como en la impartición de la justicia penal. En donde, ésta, sea más transparente, imparcial y objetiva.

Con la Reforma Constitucional Penal en comento, se tratara de impulsar un nuevo Sistema Penal que permita hacer realidad una mayor imparcialidad y transparencia en quienes procuran e imparten justicia, a través del Sistema Penal Acusatorio Adversarial, en donde, se establece el principio de presunción de inocencia, el debido proceso legal. Además, de los juicios orales y de los medios alternativos para la solución de controversias: mediación, conciliación y arbitraje. Igualmente, con la Reforma Constitucional Penal, se pretenden establecer políticas criminológicas y criminalísticas mas apegadas a la investigaron científica, a fin de lograr un trabajo más objetivo, racional y factible para beneficio de las víctimas. Consecuentemente, los beneficios son amplios y holísticos. De ahí, la urgente necesidad de realizar cambios cualitativos al interior de las facultades de derecho, que es el lugar en dónde se forman a los abogados y futuros juristas de nuestras entidades federativas del país y allende fronteras. Toda vez, que se verán impactados al verse obligados al actualizar sus conocimientos que conlleva el Sistema Penal Acusatorio Adversarial y Garantista en Materia Penal. Así como de los medios alterna-

\footnotetext{
${ }^{3}$ Kaplan, Marcos: Del Derecho y del Jurista; art. publ. en el periódico El Financiero, sección cultural "Biblioteca". México, D.F., viernes 3 de Diciembre de 1993, p. 15.

${ }^{4}$ Véase Sánchez Vázquez, Rafael: Metodología de la Ciencia del Derecho; 8 a ed. (agotada) Ed. Porrúa, S.A. México, D.F. 2008, pp. 219-252.
} 
tivos para la solución de controversias para el efecto de hacer realidad una procuración e impartición de justicia mas pronta, transparente e imparcial. En conclusión, con las investigaciones que se realizan se lograran resultados que beneficiaran al entorno académico y de la investigación jurídica, así como también, la ciudadanía logrará recobrar confianza y credibilidad en las instituciones jurídicas que procuran e imparten la justicia penal.

Al respecto, el jurista Carlos Nataren Nandayapa, expresa lo siguiente: La reciente reforma constitucional al sistema de justicia penal y de seguridad pública puede definirse como la transformación más profunda del proceso penal mexicano moderno; en efecto, desde el Congreso Constituyente de 1916, no ha existido una reforma que tenga la misma amplitud de miras y de objetivos. Ahora, una vez aprobado el nuevo texto constitucional, se abre una nueva etapa: la implementación de los principios y directrices de la reforma en el ámbito del proceso penal ordinario, etapa que, evidentemente, será una de las labores más delicadas para todos los operadores jurídicos en nuestro país. ${ }^{5}$

Durante el periodo 2007-2008, se impulsó en México la Reforma a la Justicia Penal, entre otras razones, porque tanto la Cámara de Diputados como la de Senadores del Congreso de la Unión, han aprobado la minuta proyecto de decreto por el que se reforman los artículos 16, 17, 18, 19, 20, 21, y 22; las fracciones XXI y XXIII del artículo 73; la fracción vII del artículo 115 y la fracción XIII del apartado B del artículo 123 de la Constitución Política de los Estados Unidos Mexicanos. Con el propósito de establecer el Sistema Penal Acusatorio Adversarial y Garantista, a través de los Juicios Orales, respetando el principio de presunción de inocencia.

En relación al título del presente artículo, es prudente expresar que los problemas de la corrupción y de la falta de eficacia y eficiencia de los servidores públicos que se vinculan a la procuración e impartición de la justicia penal en nuestro país, se ha hecho una reforma a la fracción XIII del apartado B del artículo 123 constitucional, que versa sobre la separación del cargo por incumplimiento de la responsabilidad en el desempeño de las funciones públicas.

Dicha reforma al artículo 123 constitucional es altamente cuestionada por algunos sectores de la sociedad mexicana. Toda vez, que en algunos casos pueden afectar derechos fundamentales del servidor público, sobre todo, cuando se prueba que, el servidor público implicado, no, tiene ninguna responsabilidad. No obstante, no podrá el servidor público reincorporarse al servicio, cualquiera que sea el resultado del juicio o medio de defensa que se hubiere promovido.

\footnotetext{
${ }^{5}$ Natarén Nandayapa, Carlos F.: Breves Reflexiones sobre algunos de los retos en el diseño del nuevo proceso penal ordinario; artículo publicado en el libro: García Ramírez, Sergio y de González Mariscal, Olga Islas (Coordinadores): La Reforma Constitucional en Materia Penal Jornadas de Justicia Penal; Coedición de: itj-unam e inacipe, México, D.F., 2009. p. 229.
} 
Dicho supuesto es por demás violatorio de los derechos fundamentales y de las garantías individuales que consagra nuestra Carta Magna, a partir de la reforma del 10 de junio de 2011. Es decir, todo acto o hecho injusto e ilegal que esté en contra de la dignidad e igualdad humana y demás derechos pro persona del servidor público violenta el garantismo que es base fundamental de la Reforma Constitucional Penal en comento. En tal virtud, la expresión "no podrá el servidor público reincorporarse al servicio público desempeñado. Lo antes citado es contrario a la epistemología garantista sustento sine qua non de la Reforma Constitucional Penal del 18 de junio de 2008. Razón por la cual, se considera que, sí se advierte y existen pruebas fehacientes para que el servidor público demuestre que no incurrió en responsabilidad en el desempeño de sus funciones, luego entonces, tendrá el derecho a ser reincorporado por parte de la institución demandada. El no hacerlo tal y como lo expresa el párrafo en comento, significa que estamos en presencia de una concepción intolerante y autoritaria, que en nada le interesa la justicia, la proporcionalidad, ni la equidad como expresiones propias de la axiología que es congruente con el Estado de Derecho Social Democrático.

\section{I BReVes Reflexiones SOBRe lOS MALES QUE AQUEJAN A LOS SERVIDORES PÚBLICOS EN MÉXICO}

Lamentablemente, en la República mexicana, la opinión pública reitera de manera frecuente su malestar en contra de la corrupción, ya que, es un problema que, por desgracia, se presenta en los tres órdenes del gobierno: en el sector privado, en las corporaciones policíacas, en la procuración y en la impartición de justicia. La corrupción no distingue filiación partidista ni posición ideológica, es un problema para todos los partidos, para el gobierno, pero es, ante todo, una grave ofensa contra la sociedad mexicana". 6

"La corrupción puede envolver promesas, amenazas o ambas; puede ser iniciada por un servidor público o un cliente interesado; puede darse con actos de omisión o comisión; puede generarse con servicios lícitos o ilícitos; puede estar dentro o fuera de una organización pública. Los límites de la corrupción son dificiles de definir y dependen de las leyes y costumbres locales. La primera tarea de un análisis de política es desagregar los tipos de comportamiento corruptos e ilícitos. Se piensa que la situación se debe, principalmente, a un sistema social que no funciona y a las grandes diferencias económicas, sociales y culturales, así como a la disparidad en la distribución del ingreso y el poder"?

\footnotetext{
${ }^{6}$ Roemer, Andrés: Economía del crimen; $1^{\text {a }}$ ed. Ed. Limusa, S.A. de C.v. México, D.F. 2001. p. 235.

${ }^{7}$ Idem. pp. 236 a 239.
} 
Por otro lado, con frecuencia se escuchan argumentos que justifican la corrupción señalando que es un mal arraigado en todos los países del mundo. Por eso las estrategias para abatir la corrupción deben estudiar las causas de raíz, el papel de los incentivos y la prevención, así como las reformas institucionales y económicas pertinentes. ${ }^{8}$

Nuestro país aún está lejos de alcanzar un auténtico Estado de derecho. En todos los eslabones del sistema de justicia se perciben ineficiencias, incertidumbre y altos costos. La seguridad pública, la procuración de justicia, el desempeño de los tribunales y el sistema penitenciario quedan rezagados ante la escalada de la delincuencia.

Esta percepción de desconfianza e ineficiencia en las instituciones de justicia y en los organismos de seguridad pública no es reciente. Ya hace más de cuatro décadas, Alfonso Teja Zabre diagnosticó que nuestro país padecía de "corrupción social, impotencia policíaca y putrefacción penitenciaria". Pero, en la actualidad, los altos índices de criminalidad, la creciente impunidad, los evidentes rezagos e ineficiencias de nuestras instituciones y, en ocasiones, los casos de contubernio entre agentes de la ley y criminales han hecho que la seguridad pública sea la demanda más enérgica de la ciudadanía y la prioridad en la agenda gubernamental. ${ }^{9}$

En 1998, de acuerdo a una publicación de la Secretaría de Gobernación, el 90\% de los delitos quedaban sin castigo. ${ }^{10}$ Para el periodo entre 1996 y 2000, el CIDAG señaló que en nuestro país la impunidad promedio fue de $96 \%$.

Para el año 2004, del total de víctimas sólo el 23\% acudió a denunciar el delito ante el Ministerio Público. El. 53\% no denunció porque lo considera una pérdida de tiempo o desconfia de la autoridad. ${ }^{11}$

En 2007, 1a impunidad fue de 98.76\% para todos los delitos. A nivel internacional los países que menos impunidad presentan son Azerbaiján

\footnotetext{
${ }^{8}$ Supra. Idem. p. 240.

${ }^{9}$ Quiroz Cuarón, Alfonso, "Crisis de la administración de justicia penal", Revista de la Facultad de Derecho de México, núms. 41-42, enero-junio de 1961, pp. 319-348. Cit. por Zepeda Lecuona, Guillermo R.: "Notas para un diagnostico de la procuración de justicia en el fuero común", art. publ. en Sergio García Ramírez: Liber ad Honorem. $1^{a}$ ed. Tomo II. Ed. Instituto de Investigaciones Jurídicas-UNAM. México, D.F. 1998. p. 1547.

${ }^{10}$ Reforma 24 de abril de 1998. Citado en siIs: Sistema de Índices e Indicadores en Seguridad Pública. http://www.mexicoevalua.org/descargables/5ela0a_sistema_de_indices-e-indicadores_en_seguridad_publica_completo_impresion_nov19.pdf. Fecha de consulta: 26 de mayo de 2012.

${ }^{11}$ Datos de la encuesta victimológica realizada por el Instituto de Estudios Ciudadanos sobre la Inseguridad (ICESI). La encuesta ENSI-3 se realizó del 15 de febrero al 15 de marzo de 2005, con información sobre el historial de victimización para todo el año 2004, con una muestra total de 66,000 cuestionarios aplicados en viviendas de las 32 entidades federativas de la República Mexicana. Cit. por Vizcaíno Zamora, Álvaro: La Formación de Agentes del Ministerio Público en Francia y México; artículo publicado por el INACIPE. http://www.inacipe.gob.mx/index.php?option=com_ content\&view $=$ article \&id=376:la-formacion-de-agentes-del-ministerio-publico-en-francia-y-mexicoautor-alvaro-vizcaino-zamora\&catid=37:alvaro-vizcaino-zamora\&Itemid=171. Fecha de consulta: 26 de mayo de 2012.
} 
(37.5\%), Bielorrusia (60.6\%), Grecia (74\%) o Inglaterra (77.4\%); en tanto que México aparece entre las naciones con mayor impunidad junto con Portugal (95\%) o Argentina (98.7\%)..$^{12}$

Desde el establecimiento de esta figura en el marco constitucional (1993), se han venido incrementando los delitos considerados como graves, lo que trae como consecuencia la sobrepoblación penitenciaria. Cabe resaltar que la mencionada figura jurídica se encuentra contemplada en el artículo 187 del CPPES, y es conforme al artículo 20, apartado "A", fracción I, de la CPEUM.

Así pues, la fórmula de delitos graves y no graves no es inconstitucional, pero contradice lo establecido en los tratados internacionales. De ahí que resulte incongruente la firma de tales ordenamientos jurídicos en los que nuestro país se compromete a respetar dichos documentos, y por otra parte, en su ley fundamental hace caso omiso a ellos. ${ }^{13}$

El modelo procesal penal contempla derechos a favor del inculpado, como por ejemplo, el de ser juzgado en audiencia pública por un juez (principio de publicidad); sin embargo, los juzgados no cuentan con la infraestructura necesaria, y mucho menos existe la cultura de la participación ciudadana en audiencias celebradas durante las etapas de instrucción y juicio. Cuando se llevan a cabo las audiencias, los familiares, ya sea del ofendido o de la víctima, con poca frecuencia se presentan a éstas. Excepcionalmente, estudiantes y ciudadanos asisten. Por lo anterior, en la práctica, esta garantía individual no se satisface cabalmente. La situación se agrava en centros penitenciarios de alta seguridad como, por ejemplo, Almoloya (donde en ocasiones se celebran actuaciones judiciales de desahogo de pruebas), debido a la restricción para ingresar a tales lugares.

Dificilmente se puede hablar de respeto a principios elementales rectores del proceso penal, como son el de inmediación (que las pruebas se practiquen ante quien va juzgar, es decir, el juez), pues una gran cantidad de ellas se desahogan ante un órgano diverso; es decir, el Ministerio Público, que en la etapa de proceso se convierte en parte acusadora. Inclusive, en las pruebas que se desahogan en la etapa judicial, el juez no siempre se encuentra presente, tal y como se desprende de las entrevistas a ellos. ${ }^{14}$

Además, cabe resaltar otro problema palpable tiene que ver con las irregularidades que se cometen cotidianamente, por parte de los jueces, debido a que firman diligencias (declaraciones testimoniales, careos, declaraciones

\footnotetext{
12 Índices creados por Guillermo Zepeda. Disponible en www.cidac.org. Citado por siss: Sistema de Índices e Indicadores en Seguridad Pública. Ibídem.

${ }^{13}$ Idem. p. 83.

Nota: Lo remarcado en negritas es para resaltar el contenido.

${ }^{14}$ Nota: Lo remarcado en negritas es para resaltar el contenido.

Guillén, López, Raúl, Cruz Covarrubias, Armando E.; Guillén, López, Raúl, Cruz Covarrubias, Armando E.: La justicia penal en México. Un estudio de caso; $1^{a}$ ed. Ed. Instituto de Investigaciones Jurídicas de la unam, México, D.F. 2008, p. 84.
} 
preparatorias y otras) en las que no están presentes; sin bien, ello se debe a la carga laboral, no tiene justificación desde el punto de vista legal. Del mismo modo, los defensores y el Ministerio Público incurren en este tipo de responsabilidades al firmar las actas que fueron celebradas, violando no sólo las formalidades del procedimiento, sino también derechos y garantías individuales del inculpado. Cabe resaltar en este punto la impunidad con que se cometen dichas irregularidades, sin sanción administrativa o penal alguna, pues sólo basta asistir a cualquier juzgado, ya sea en materia federal o local para percatarse de ello.

Los problemas que presentó el modelo de justicia penal sonorense no son exclusivos de dicho estado, ya que dicha problemática también ocurre en otras entidades federativa y en el ámbito federal, dicha tarea corresponde a los legisladores, operadores del derecho e investigadores, cuyas propuestas deberán ser consideradas en la búsqueda de un nuevo sistema de justicia penal más justo y equilibrado.

Es necesaria una reforma integral que garantice los aspectos siguientes: sistema acusatorio, equilibrio procesal, respeto a los principios de contradicción, inmediación, publicidad y celeridad. ${ }^{15}$

\section{I . DESCRIPCIÓN Y ANÁLISIS JURÍdICO SOBRE \\ LA SEPARACIÓN DEL CARGO POR INCUMPLIMIENTO DE LA RESPONSABILIDAD EN EL DESEMPEÑO DE SUS FUNCIONES}

En todo lo ancho y largo de la República Mexicana, en términos generales se comparte de manera reiterada una opinión pública y práctica social de incertidumbre acerca del quehacer cotidiano de la seguridad pública, la procuración e impartición de la justicia, entre otras razones, porque dichas actividades se ven afectadas tanto por la falta de credibilidad, honestidad, como de la presencia de escenarios de corrupción, mentiras, ineficacia e ineficiencia.

Así pues, la aspiración e intención de contar con agentes ministeriales y policías eficientes, honestos y confiables, que puedan combatir de forma profesional, ética y efectiva la delincuencia, es una preocupación que dio origen a la reforma al artículo 123 constitucional de fecha 3 de marzo de 1999. En esa ocasión el constituyente pretendió incorporar mecanismos más eficientes para separar de la función a los elementos que, por cualquier circunstancia, se apartaran de los principios rectores de la carrera policial. Al efecto, se señaló que: “...Los buenos elementos de las instituciones policiales y de seguridad pública deben contar con sistemas que les permitan hacer una carrera profesional, digna y reconocida por la sociedad". ${ }^{16}$

\footnotetext{
${ }^{15}$ Guillén, López, Raúl, Cruz Covarrubias, Armando E.; Op. cit. p. 85.

${ }^{16}$ Cámara de Diputados: Poder Legislativo, Lx Legislatura, Diario de los Debates, Primer Periodo de
} 
Además, se retoma como prioridad elevar el nivel de calidad de vida de los agentes del ministerio público, miembros de corporaciones policiales y peritos, así como de sus familias y dependientes, mediante sistemas complementarios de seguridad social que podrán establecer las autoridades del gobierno federal, de las entidades federativas y de los municipios a favor de ellos.

Lo anterior buscaba remover de las instituciones de seguridad pública y de procuración de justicia a los malos elementos, sin que procediese su reinstalación, cualquiera que hubiera sido el sentido de la resolución jurisdiccional respecto del juicio o medio de defensa promovido y, en caso de que aquélla resultara favorable para los quejosos, sólo tendrían derecho a una indemnización.

Sin embargo, posteriormente diversos criterios judiciales permitieron, de hecho, la reinstalación de dichos elementos a sus cargos. Ello debido a que, las sentencias de amparo, aún y cuando sean sólo para efectos, producen como consecuencia que las cosas regresen al estado en que se encontraban y, por consecuencia, a que el mal servidor público permanezca en la institución. ${ }^{17}$

Ante ello, la intención de la presente reforma a la fracción XIII del Apartado B, del artículo 123, es determinar que en caso de incumplir con las leyes que establezcan las reglas de permanencia o al incurrir en responsabilidad en el desempeño de sus funciones, los agentes del ministerio público, los peritos, y los miembros de las instituciones policiales de la federación, el Distrito Federal, los estados y los municipios serán separados o removidos de su cargo sin que proceda, bajo ningún supuesto, la reinstalación o restitución en sus cargos por significar una falta a los valores institucionales de rectitud y alto valor ético que se requiere en el sistema de seguridad pública e impartición de justicia, que es pieza fundamental en el espíritu de la reforma.

Se ha considerado importante incluir a los agentes del ministerio público y peritos en ésta previsión constitucional, en la medida que son elementos fundamentales en el proceso de procuración de justicia e investigación y se requiere mantener su desempeño en los principios de profesionalismo, la ética y eficiencia plena en sus ámbitos laborales.

La confiabilidad de los dictámenes periciales constituye un elemento trascendental para las resoluciones del órgano jurisdiccional en su ámbito de competencia, y en su caso, le permite a la autoridad ministerial perfeccionar la integración de las indagatorias para una mejor persecución de delitos, en tanto que a la persona imputada le otorga mayores mecanismos de defensa ante una posible imputación infundada. ${ }^{18}$

\footnotetext{
Sesiones Ordinarias del Segundo Año de Ejercicio, Diario No. 35, miércoles 12 de diciembre de 2007. http://cronica.diputados.gob.mx. Fecha de consulta 25 de mayo de 2012.

${ }^{17}$ Cámara de Diputados: Poder Legislativo, lx Legislatura, Diario de los Debates, Primer Periodo de Sesiones Ordinarias del Segundo Año de Ejercicio, Diario No. 35, miércoles 12 de diciembre de 2007. http://cronica.diputados.gob.mx. Fecha de consulta 25 de mayo de 2012.

${ }^{18}$ Ibidem.
} 
Dichas deficiencias, sin lugar a dudas en parte han motivado la Reforma Constitucional Penal del 18 de junio de 2008, en donde se pretende establecer un mayor respeto a la legalidad, honradez, profesionalismo, eficacia y eficiencia, en la actividad de quienes se desempeñan en la seguridad pública. Así como de la procuración e impartición de justicia.

Por su parte, Jorge Madrazo Cuéllar, considera que: De acuerdo con la interpretación jurisprudencial, la relación del Estado con sus empleados es de naturaleza administrativa, sin embargo, en beneficio y protección de los empleados del Estado ésta se transformó con objeto de equiparla a un vínculo de índole laboral, constituyéndose el Estado en una especie de patrón sui generis. La relación específica entre los militares, marinos, miembros de los cuerpos de seguridad pública y el personal del servicio exterior y del Estado, quedó al margen de esta equiparación, ya que de conformidad con lo dispuesto por la fracción XIII, apartado B, del artículo 123 constitucional, dicha relación se rige por sus propias leyes y no por la Ley Federal de los Trabajadores al Servicio del Estado. ${ }^{19}$

Para definir la naturaleza de la relación, la reforma propuso que los miembros de las instituciones de seguridad pública fueran considerados como trabajadores de confianza y se rigiesen conforme a sus propias leyes, gozando de las medidas de protección al salario y los beneficios de la seguridad social.

A fin de salvaguardar los fines de la seguridad pública, contar con mejores elementos y tener la posibilidad real de adecuar conforme a derecho las estructuras policiacas en beneficio de la sociedad mexicana, la iniciativa planteó que los miembros de las instituciones o cuerpos de seguridad pública no tendrían acción de reinstalación para el caso de baja, cese, destitución, remoción, separación o terminación de los efectos del nombramiento. Con esto se pretendió dotar a las corporaciones policiacas de herramientas que les permitieran depurar a los cuerpos de seguridad pública. La reforma propuesta no anularía el servicio civil de carrera, su propósito era garantizar que la función de seguridad pública se desarrollara con estricto apego a los principios constitucionales de legalidad, eficiencia, profesionalismo y honradez. ${ }^{20}$ Lo anteriormente expresado se considera adecuado. Sin embargo, lo que no se puede aceptar en un Estado de Derecho Social Democrático, es lo relativo a que, sí, el servidor público es inocente no se le pueda reincorporar a sus funciones. Dicha negativa es totalmente aberrante para la cultura jurídica y para el paradigma del Estado de Derecho Democrático.

\footnotetext{
${ }^{19}$ Madrazo Cuéllar, Jorge: Las reformas constituciones en materia penal; http://www.juridicas.unam. $\mathrm{mx} / \mathrm{publica} / \mathrm{rev} / \mathrm{cconst} / \mathrm{cont} / 1 / \mathrm{cl} / \mathrm{cl11}$.htm. Fecha de consulta 20 de junio de 2012.

${ }^{20}$ Ibidem.
} 
Por otra parte, se hace referencia de la información que se discutió en la Cámara de Senadores, respecto a la fracción XIII del artículo 123 Constitucional:

\begin{abstract}
"Si la autoridad jurisdiccional resolviera que la separación, remoción baja o cese o cualquier otra forma de terminación del servicio fue injustificado, el estado sólo estará obligado a pagar la indemnización..$^{21}$ ¿De qué se trata esta disposición?

Fíjense nada más, a cualquier Ministerio Público, perito, policía se le podrá despedir, se le podrá cesar, se le podrá remover, si este policía, perito o trabajador de los órganos de justicia, de los órganos de procuración de justicia acude a la Junta de Conciliación o acude a los tribunales federales y ganan los juicios, y demuestra el trabajador que fue injustificado su despido y que el cese fue injustificado y fue falsa la argumentación que le esgrimieron para cesarlo y despedirlo, aún así el trabajador no tendrá derecho a que se le reinstale. Por eso no puede tratarse diferente a ningún ciudadano y no puede establecerse en la Constitución una restricción de tal naturaleza. Yo sé por qué es.

En la Procuraduría General de la República, en los últimos años, han despedido a agentes del AFI y agentes de la antigua Policía Judicial Federal, sin causa justificada, sólo por situaciones de carácter político. Los cesaron, interpusieron los recursos, acudieron al Tribunal, ganaron el juicio laboral y la autoridad laboral ordenó se reinstalaran a esos agentes cesados todas las demandas que han interpuesto este tipo de trabajadores de órganos de procuración de justicia, casi todas las demandas las han ganado.

Y ahora a nivel de rango constitucional establecen la prohibición y
\end{abstract}

\footnotetext{
${ }^{21}$ Cámara de Senadores: Poder Legislativo, Lx Legislatura, Diario de los Debates, primer Periodo de Ordinario de Sesiones del Segundo Año de Ejercicio, Diario No. 34, 13 de diciembre de 2007.

http://www.senado.gob.mx/index.php?ver=sp\&mn=3\&sm=3\&lg=LX_II\&id=759. Fecha de consulta 25 de junio de 2012.

- El C. Presidente Creel Miranda: Muchas gracias, Senador Monreal.

Solicito a la Secretaría dé lectura a la propuesta de modificación que acaba de dar lectura el Senador Monreal al artículo 123 en su fracción XIII e inmediatamente consulte a la Asamblea, en votación económica, si se admite a discusión.

- El C. Secretario Rivera Pérez: La propuesta consiste en suprimir la fracción XIII del artículo 123. Consulto a la Asamblea, en votación económica, si se admite a discusión. Quienes estén por la afirmativa, favor de levantar la mano.

(La Asamblea asiente)

Quienes estén por la negativa, favor de levantar la mano.

(La Asamblea no asiente)

No se admite a discusión, señor Presidente.

- El C. Presidente Creel Miranda: En consecuencia, ábrase el sistema electrónico de votación, hasta por un minuto, para recoger la votación nominal del artículo 123 en su fracción XIII.
} 
la restricción para que a un trabajador que fue vejado, cesado, que fue injustamente despedido, se le pueda reinstalar y restituir en su honra y en su prestigio personal.

No puede establecerse eso en la Constitución, me parece delicado y me parece grave.

Por eso nos oponemos y por eso quisiéramos proponerle al Presidente de la Mesa Directiva de la Cámara que someta a la consideración de la Asamblea la supresión de esta disposición contenida en la fracción XIII del artículo $123 .^{22}$

A partir de la Reforma Constitucional Penal del 18 de junio de 2008, en el apartado в Fracción XIII artículo 123 constitucional, se estableció la separación del cargo por incumplimiento de la responsabilidad en el desempeño de las funciones públicas, de los siguientes servidores públicos: agentes del Ministerio Público, los peritos y los miembros de las instituciones policiales de la Federación, el Distrito Federal, los Estados y los Municipios, quedando el texto del artículo en la parte correspondiente, de la siguiente manera:

Artículo 123. Toda persona tiene derecho al trabajo digno y socialmente útil; al efecto, se promoverán la creación de empleos y la organización social de trabajo, conforme a la ley.

Apartado B...

XIII. Los militares, marinos, personal del servicio exterior, agentes del Ministerio Público, peritos y los miembros de las instituciones policiales, se regirán por sus propias leyes.

Los agentes del Ministerio Público, los peritos y los miembros de las instituciones policiales de la Federación, el Distrito Federal, los Estados y los Municipios, podrán ser separados de sus cargos si no cumplen con los requisitos que las leyes vigentes en el momento del acto señalen para permanecer en dichas instituciones, o removidos por incurrir en responsabilidad en el desempeño de sus funciones. $\mathrm{Si}$ la autoridad jurisdiccional resolviere que la separación, remoción, baja, cese o cualquier otra forma de terminación del servicio fue injustificada, el Estado sólo estará obligado a pagar la indemnización y demás prestaciones a que tenga derecho el servidor público, sin que en ningún caso proceda su reincorporación al servicio, cualquiera que sea el resultado del juicio o medio de defensa que se hubiere promovido. $^{23}$

\footnotetext{
${ }^{22}$ Cámara de Senadores: Poder Legislativo, Lx Legislatura, Diario de los Debates, primer Periodo de Ordinario de Sesiones del Segundo Año de Ejercicio, Diario No. 34, 13 de diciembre de 2007. Fuente de Consulta: http://www.senado.gob.mx/index.php?ver=sp\&mn=3\&sm=3\&lg=LX_II\&id=759

${ }^{23}$ Cámara de Diputados: Reformas a la Constitución; Reformas Constitucionales en Orden Cronológico, Reforma Penal Constitucional de 18 de junio de 2008. Fuente de consulta: http://www.diputados.
} 
Por lo anteriormente expuesto, a continuación, se hace un breve análisis, acerca de la sanción administrativa y/o política a que se refiere el artículo citado.

"La falta de cumplimiento de los deberes de la función pública por los trabajadores públicos origina responsabilidades de naturaleza diversa con respecto de la administración pública y de terceros. ${ }^{24}$

"El funcionario y el empleado público están subordinados a la ley y a su debido cumplimiento, por esto, están obligados a responder de sus actos públicos. La responsabilidad de la función pública es la obligación en que se encuentra el servidor del Estado que ha infringido la ley, por haber cometido un delito, una falta, o ha causado una pérdida o un daño, y debe responder por ella.

"El trabajador al servicio del Estado en el desempeño de su cargo puede incurrir en faltas o delitos, que deben ser reprimidas para mantener una eficaz y justa administración. Esto provoca los diversos tipos de responsabilidad: la política, la administrativa, la penal y la civil". 25

"Se aplicarán sanciones administrativas a los servidores públicos por los actos u omisiones que afecten la legalidad, honradez, lealtad, imparcialidad y eficiencia que deban observar en el desempeño de sus empleos, cargos o comisiones. ${ }^{26}$

Por lo que respecta, al estudio del concepto de responsabilidad, cabe hacer mención que la doctrina jurídica ha expresado lo siguiente:

Así pues, para el Jurista Rolando Tamayo y Salmoran, quien se ha especializado en la Jurisprudencia Analítica, en la Teoría del Derecho, y de manera profunda conocedor de la Estructura de la Norma Jurídica, al tratar el concepto de responsabilidad, expresa que es un concepto muy amplio, toda vez, que considera:

La 'responsabilidad' constituye un concepto jurídico fundamental. Sin embargo, la noción de responsabilidad no es exclusiva del discurso jurídico. 'Responsabilidad' se usa en el discurso moral y religioso, así como en el lenguaje ordinario. La voz 'responsabilidad' proviene de 'respondere' que significa, inter alia: 'prometer', 'merecer', 'pagar'. Así, 'responsalis' significa: 'el que responde' (fiador). En un sentido más restringido 'responsum' ('responsable) significa: 'el obligado a responder de algo o de alguien'. 'Respondere' se encuentra

gob.mx/LeyesBiblio/ref/dof/CPEUM_ref_180_18jun08.pdf. Fecha de consulta: 18 de mayo de 2012. Nota: Lo remarcado en negritas es para resaltar el contenido.

${ }^{24}$ Sánchez Gómez, Narciso: Primer curso de Derecho Administrativo; $1^{\mathrm{a}}$ ed. 1998, 4ª ed. Ed. Porrúa, S.A. de C.V. México, D.F. 2005, p. 424.

${ }^{25}$ Serra Rojas, Andrés: Derecho Administrativo. Doctrina, Legislación y Jurisprudencia, primer curso; $1^{\text {a }}$ ed. 1959, $23^{\text {a }}$ corregida y aumentada por Andrés Serra Rojas Beltri, Ed. Porrúa, s.A. de c.v. México, D.F. 2002. p. 501.

${ }^{26}$ Serra Rojas, Andrés, Op. cit. 498. 
estrechamente relacionada con 'spondere', la expresión solemne en la forma de la stipulatio, por la cual alguien asumía una obligación (Gayo, Inst., 3, 92), así como 'sponsio", palabra que designa la forma más antigua de obligación (A. Berger). Para la dogmática jurídica: un individuo es responsable cuando, de acuerdo con el orden jurídico, es susceptible de ser sancionado (H. Kelsen). En este sentido la responsabilidad presupone un deber (del cual debe responder el individuo). La responsabilidad señala quién debe responder del cumplimiento o incumplimiento de tal obligación.

Existen dos grandes formas de aplicar la responsabilidad: la llamada responsabilidad por culpa y la conocida como responsabilidad objetiva o absoluta.

La responsabilidad por "culpa" implica la aplicación de sanciones al individuo considerado responsable supone "culpa" por parte del autor del hecho ilícito, ya que tuvo la intención de cometerlo o bien habiéndolo previsto no lo impidió. A la responsabilidad objetiva, por el contrario, no le importa la culpa del autor; hasta que el hecho ilícito le realice (con o sin culpa del autor) para que se apliquen las consecuencias de sanción al individuo considerado responsable (esto es, por lo general, el sistema de responsabilidad en los accidentes de trabajo). ${ }^{27}$

Por su parte, Fanny Pineda, aborda el concepto de Responsabilidad del Estado, en los siguientes términos:

Es la obligación que tiene el Estado de proteger jurídicamente a los ciudadanos contra decisiones arbitrarias e ilícitas de la administración pública: federal y estatal, y de sus funcionarios indemnizándolos del daño causado mediante una compensación económica que restituya el perjuicio patrimonial e inclusive moral que el Estado ocasione como consecuencia de la actividad administrativa que desempeña en cumplimiento de las funciones que le han sido encomendadas. ${ }^{28}$

En este orden de ideas, el destacado Jurista Dr. José Luis Soberanes Fernández, quien se ha destacado a la investigación científica de las Instituciones Históricas del Derecho Novohispano. Así como del Derecho Patrio y demás

\footnotetext{
${ }^{27}$ Tamayo y Salmoran, Rolando: Responsabilidad; artículo publicado en: Diccionario Jurídico Mexicano, Rep-z; Tomo viII, en coedición por el Instituto de Investigaciones Jurídicas de la unAm y Porrúa, México, 1984. pp. 14 y 15.

${ }^{28}$ Pineda, Fanny: Responsabilidad del Estado; artículo publicado en: Diccionario Jurídico Mexicano, Rep-Z; Tomo VIII, en coedición por el Instituto de Investigaciones Jurídicas de la unam y Porrúa, México, 1984. pp. 47 y 48
} 
Instituciones Jurídicas del Sistema Jurídico Mexicano Contemporáneo, y quien hace un par de años escribió un excelente trabajo sobre el origen de las declaraciones de Derechos Humanos, al tratar el concepto de Responsabilidades de los servidores públicos, expresa lo siguiente:

El sistema vigente de responsabilidades de servidores públicos trae la novedad de la responsabilidad administrativa. Creemos que es muy loable el esfuerzo que el actual régimen, dentro del llamado programa de renovación moral de la sociedad, ha hecho por establecer este nuevo sistema de responsabilidades oficiales, la creación de la Secretaría de la Contraloría General de la Federación y sobre todo la voluntad política de acabar con la corrupción. ${ }^{29}$

La suspensión del empleo, cargo o comisión. Es la privación temporal de las labores de trabajo dentro de alguno de los Poderes del Estado de un servidor público para desempeñar la función que tiene conferida legalmente, así como la remuneración que es consecuente de la misma, por el tiempo que dure la suspensión. ${ }^{30}$

La destitución del empleo, cargo o comisión. Es la terminación de los efectos del nombramiento o de la elección de un servidor público, como consecuencia de una resolución administrativa expedida por autoridad competente que le ha fincado una responsabilidad administrativa, y como consecuencia de la gravedad de la infracción se hace acreedor a esa sanción, que viene prácticamente a extinguir la relación laboral entre una persona física y el Estado.

Esta sanción administrativa ha provocado polémica, en virtud que de conformidad con la Ley Federal de los Trabajadores al Servicio del Estado, según su artículo 46, fracción $\mathrm{v}$, para suspender o destituir a un trabajador del Estado, compete al Tribunal Federal de Conciliación y Arbitraje dictar la resolución respectiva y siempre y cuando se justifiquen algunas de las causas que en la misma fracción se especifican, de tal manera que los sostenedores de esta tesis conciben que a las autoridades administrativas no les compete destituir a dichos trabajadores, y cuando lo hagan estaremos ante medidas ilegales o arbitrarias. ${ }^{31}$

En efecto, se trata de una sanción administrativa que ha provocado muchas inconformidades de los servidores públicos, y como consecuencia han hecho valer los medios de defensa legal que establece a su favor la legis-

\footnotetext{
${ }^{29}$ Soberanes Fernández, José Luis: Responsabilidades de los servidores públicos; artículo publicado en: Diccionario Jurídico Mexicano, Rep-Z; Tomo vIII, en coedición por el Instituto de Investigaciones Jurídicas de la unam y Porrúa, México, 1984. p. 52.

${ }^{30}$ Sánchez Gómez, Narciso; Op. cit. p. 440.

${ }^{31}$ Idem. p. 442.
} 
lación burocrática, porque insisten que corresponde solamente al Tribunal de Conciliación y Arbitraje, Federal y Local, resolver lo conducente, si es procedente o no, la destitución de alguno de ellos en el ejercicio de una función pública, siempre y cuando la sanción en cuestión se finque conforme a la Ley Federal de los Trabajadores al Servicio del Estado, porque no debe quedar en manos de las autoridades administrativas resolver y ejecutar por su propia cuenta esta clase de sanciones, a lo sumo les compete demandar dicha medida ante los mencionados Tribunales acompañando las pruebas suficientes, para que jurisdiccionalmente se emita el fallo respectivo. Sin embargo, cuando tal medida se apoye en la Ley Federal de Responsabilidades de los Servidores Públicos, sí debe aplicarse por la autoridad administrativa competente que señala dicho cuerpo legal, pero se requiere más precisión normativa, para evitar confusiones. ${ }^{32}$

\section{Algunas tesis SOBRe la Responsabilidad EN EL DESEMPEÑO DE LA FUNCIÓN PÚBLICA EMITIDAS POR EL PODER JUDICIAL DE LA FEDERACIÓN}

\begin{tabular}{|c|c|c|c|}
\hline Tesis & Semanario Judicial de la Federación & Quinta Época & 3235591 de 1 \\
\hline Segunda Sala & LXXX & Pág. 848 & \\
\hline \multicolumn{4}{|c|}{ [TA]; 5a. Época; 2a. Sala; S.J.F.; LXXX; Pág. 848} \\
\hline \multicolumn{4}{|c|}{ Empleados públicos o funcionarios, responsabilidad en que pueden incurrir los. } \\
\hline \multicolumn{4}{|c|}{$\begin{array}{l}\text { El funcionario o empleado público es responsable del incumplimiento de los deberes } \\
\text { que le impone la función que desempeña. La responsabilidad puede ser de índole } \\
\text { administrativa, civil o penal. La responsabilidad administrativa se origina por la co- } \\
\text { misión de faltas disciplinarias y da lugar a la imposición de correcciones de carácter } \\
\text { también disciplinarias. La fracción I, del artículo 238, del Reglamento de la Ley Or- } \\
\text { gánica de la Contraloría de la Federación, que establecía las tres clases de responsa- } \\
\text { bilidades que se acaban de mencionar, definía la primera de ellas en los siguientes } \\
\text { términos: administrativas, cuando se refieren a faltas u omisiones en el desempeño de } \\
\text { las labores y que pueden ser corregidas mediante procedimientos puramente admi- } \\
\text { nistrativos. Se está en presencia de la responsabilidad civil cuando el incumplimiento } \\
\text { de las obligaciones públicas se traduce en un menoscabo en el patrimonio del Esta- } \\
\text { do. En este caso se trata de una responsabilidad exclusivamente pecuniaria, que se } \\
\text { establece con el único fin de resarcir al Estado de los daños sufridos. La fracción II, } \\
\text { del precepto invocado, consideraba como responsabilidades de ese tipo aquellas que } \\
\text { provengan de faltas o errores cometidas en el manejo de fondos o bienes que traigan } \\
\text { aparejada la pérdida o menoscabo de dichos bienes; o las que se originen por no satis- } \\
\text { facer las prestaciones derivadas de contratos celebrados con el Gobierno Federal o sus } \\
\text { dependencias; y por último, las que emanan de la comisión de un delito y se incurre } \\
\text { en responsabilidad penal cuando en el ejercicio de sus funciones, el empleado o fun- } \\
\text { cionario ejecuta un hecho que la ley considera como delito. La fracción III, del mismo }\end{array}$} \\
\hline
\end{tabular}

${ }^{32}$ Sánchez Gómez, Narciso; Op. cit. p. 443. 
artículo 238, empleaba la siguiente definición: penales, cuando provengan de delitos o faltas previstos por la ley penal. La fuente de las tres clases de responsabilidades se encuentra en la ley, de tal manera que en todo caso tendrá que ocurrirse al derecho positivo para determinar la responsabilidad correspondiente a un hecho determinado, si el autor puede ser simultáneamente responsable en los tres órdenes, por la misma falta, y la autoridad puede declararla. Ahora bien, si el quejoso era empleado federal y al entregar el puesto que desempeñaba, se encontró un faltante en las existencias que estaban bajo su guarda, y la autoridad administrativa considerando que el faltante de bienes de la Federación podría constituir la comisión de un delito, y por lo mismo, que se estaba en el caso de responsabilidad penal, denunció los hechos al Ministerio Público, y éste ejercitó la acción penal correspondiente, se dictó auto de formal prisión contra el quejoso por el delito de peculado, y se sobreseyó en el proceso por haber formulado el representante social conclusiones no acusatorias, si posteriormente al sobreseimiento de la causa, la autoridad administrativa dictó una resolución estableciendo la responsabilidad civil del quejoso, por el faltante de bienes, en el caso tiene que recurrirse a la legislación vigente en la época de estos hechos y estimarse que en la Ley Orgánica de la Contraloría de la Federación y en su reglamento, que estaban en vigor, se encuentran las disposiciones legales que regulan el caso. El reglamento nombrado establecía las tres clases de responsabilidades ya señaladas, en que podía incurrir un empleado o funcionario del Estado, además, del estudio de los preceptos relativos de ambos ordenamientos, se desprende que la autoridad administrativa contaba con facultades para declarar la responsabilidad civil; en efecto, el artículo 21 de la ley decía textualmente: "Es facultad del contralor constituir las responsabilidades administrativas, civiles, y penales en que incurran los funcionarios, empleados y agentes del gobierno, con manejo de fondos y bienes de la nación, y que se descubran con motivo de la inspección y glosa de sus cuentas."; pero en materia de responsabilidad de carácter civil, la facultad concedida a la contraloría no era absoluta, es decir, no podía ejercitarla indistintamente en todos los casos. En efecto, el artículo 25 del mismo ordenamiento prescribía lo siguiente: "Si se tratare de responsabilidades de carácter civil que no pudieren hacerse efectivas por la vía administrativa, el contralor comunicará todos los antecedentes del caso al procurador de la República, a efecto de que ejercite las acciones correspondientes." La redacción del precepto que se acaba de transcribir permite establecer que el legislador previó dos situaciones, a saber: cuando la responsabilidad civil se podía hacer efectiva por el procedimiento administrativo y cuando esta responsabilidad solamente se podía hacer efectiva por el procedimiento judicial. La gravedad del problema se acentúa ante el silencio de la ley, pues ni la Ley Orgánica de la Contraloría de la Federación, ni su reglamento, ni en la Ley sobre Garantías del manejo de Funcionarios y Empleados Públicos, ni en la Ley Orgánica de la Tesorería de la Federación, vigentes en la época en que se desarrollaron los hechos, se encuentra ninguna disposición que resuelva el problema. Ante la omisión en que incurrió el legislador, al dejar de establecer normas expresas que rigieran las dos situaciones que prevé el artículo 25 transitorio, la Segunda Sala de la Suprema Corte considera que la solución del problema se encuentra en la debida interpretación que se dé al principio constitucional de separación de poderes, en relación con la materia que forma la base de la competencia de ellos. Es desde luego indudable que si por una materia, su naturaleza tiene un carácter judicial, ella no puede ser asignada indistintamente al Poder Judicial o al Poder Administrativo, sino que tendrá que ser encargada al poder que conforme a la ley tiene la facultad de juzgar, es decir, al Poder Judicial. Pero puede ocurrir que el caso de responsabilidad civil de que se trate, se haya originado con motivo de bienes que el Estado tiene destinados de una manera directa a la realización de sus atribuciones y que, por consecuencia, están sujetos a su régimen especial de derecho, al régimen de 
derecho público, cuyas normas son diversas de las de derecho privado, en el cual los conflictos que surjan, sólo pueden ser resueltos por una autoridad imparcial ajena a los intereses en discusión. Pues bien, cuando la vinculación de los bienes a la realización de las atribuciones del Estado, determina que su régimen sea el de derecho público, y la ley puede apartar del conocimiento de los tribunales judiciales, el conocimiento de los conflictos que respecto de ellos surjan, y establecer procedimientos administrativos que en una forma expedita les den fin y permitan que el Estado pueda, sin dilaciones, recobrar los bienes necesarios para cumplir sus atribuciones. En estos principios se basa el procedimiento administrativo sumario para hacer efectivos los impuestos y en ellos debe descansar también la posibilidad de constituir administrativamente la responsabilidad civil contra los que indebidamente manejen los fondos públicos, formados por la recaudación de impuestos. De otro modo no habría congruencia en un sistema que por una parte autoriza la acción directa contra los particulares para el cobro de las contribuciones, fundado en la ingente necesidad de obtenerlas para sostenimiento del Estado, y que por otra parte, repudiara la misma acción directa contra los empleados públicos que impidieron la aplicación de esos fondos públicos, disponiendo de ellos o perdiéndolos por negligencia; y si lo mismo puede repetirse de otros bienes, distintos de dineros públicos, que tengan la misma afectación que éstos y que, en consecuencia, estén sujetos también a un régimen exorbitante del derecho común, no puede hacerse la misma afirmación tratándose de bienes no sujetos a ese régimen especial, es decir, tratándose de bienes que, aunque del Estado, quedan sujetos a las normas del derecho común, pues en tal caso no existe ya esa vinculación directa entre los propios bienes y la realización de las atribuciones del Estado que existe en la situación anterior, y que, por lo mismo, no puede haber razón constitucional para dar al Poder Administrativo una competencia que normalmente corresponde al Judicial. en consecuencia, el artículo 25 de la ley de contraloría, que prevé la posibilidad del procedimiento judicial o del procedimiento administrativo, para hacer efectiva la responsabilidad civil, tendrá que ser interpretado partiendo de las consideraciones y distinción que se han expuesto, y en vista de ellas concluir que el procedimiento administrativo sólo será posible cuando la responsabilidad se haya contraído con motivo de bienes sujetos a un régimen de derecho público, y que el procedimiento judicial tendrá lugar cuando se trate de bienes sujetos al derecho común. En el caso, la responsabilidad civil tiene su origen en el faltante que se estima existe de bienes muebles, enseres, herramientas y refacciones que formaban parte de las existencias del garaje central de los establecimientos fabriles y militares, y como no existía en la época de los hechos, ninguna disposición legal que sujetara dichos bienes de las normas del derecho común, ni existe prueba alguna de que esos bienes estaban vinculados directamente al cumplimiento de las atribuciones del Estado, no se puede estar dentro de la autorización de la ley, para seguir el procedimiento administrativo; y por tanto, debe establecerse que la declaración administrativa de que la parte quejosa es civilmente responsable de la pérdida de diversos objetos del garaje central de referencia, es violatoria de garantías que consagran los artículos 14 y 16 constitucionales, debiendo concedérsele el amparo. Ahora bien, asentado lo anterior, surge inmediatamente el siguiente problema: en qué casos era procedente y en cuáles era improcedente la vía administrativa; o empleando los términos del legislador, cuándo se podía hacer efectiva la responsabilidad de carácter civil por las autoridades administrativas.

Amparo administrativo en revisión 1203/42. Quesnel Acosta Gorgonio. 19 de abril de 1944. Unanimidad de cuatro votos. El Ministro Franco Carreño no intervino en este asunto por las razones que se asientan en el acta del día. Relator: Gabino Fraga 


\begin{tabular}{|l|l|l|l|}
\hline TesisI.7o.A.815 A (9a.) & $\begin{array}{l}\text { Semanario Judicial } \\
\text { de la Federación y su } \\
\text { Gaceta }\end{array}$ & $\begin{array}{l}\text { Décima } \\
\text { Época }\end{array}$ & 1602051 de 198 \\
\hline $\begin{array}{l}\text { SÉPTIMO TRIBUNAL } \\
\text { COLEGIADO EN MATERIA } \\
\begin{array}{l}\text { ADMINISTRATIVA DEL } \\
\text { PRIMER CIRCUITO. }\end{array}\end{array}$ & $\begin{array}{l}\text { Libro VI, Marzo de } \\
\text { 2012, Tomo } 2\end{array}$ & $\begin{array}{l}\text { Pág. } \\
1300\end{array}$ & $\begin{array}{l}\text { Tesis Aislada } \\
\text { (Común) }\end{array}$ \\
\hline
\end{tabular}

[TA]; 10a. Época; T.C.C.; S.J.F. y su Gaceta; Libro VI, Marzo de 2012, Tomo 2; Pág. 1300

POLICÍA FEDERAL MINISTERIAL. ES IMPROCEDENTE CONCEDER LA SUSPENSIÓN EN EL AMPARO A SUS AGENTES CONTRA LOS EFECTOS Y CONSECUENCIAS DE LOS ACTOS DENTRO DEL PROCEDIMIENTO DE SEPARACIÓN DEL SERVICIO DE CARRERA DE PROCURACIÓN DE JUSTICIA FEDERAL, POR NO SER DE DIFÍCIL REPARACIÓN.

La Primera Sala de la Suprema Corte de Justicia de la Nación en la jurisprudencia la./J. 106/2010, publicada en el Semanario Judicial de la Federación y su Gaceta, Novena Época, Tomo XXXIII, enero de 2011, página 372, de rubro: "POLICÍA FEDERAL MINISTERIAL. SUS AGENTES PERTENECEN CONSTITUCIONALMENTE A UN RÉGIMEN ESPECIAL DONDE NO PUEDE RECLAMARSE LA POSIBLE AFECTACIÓN A DERECHOS LABORALES COMO EL DE ESTABILIDAD EN EL EMPLEO O CARGO O INMUTABILIDAD DE LAS CONDICIONES DE PERMANENCIA.", estableció que acorde con el artículo 123, apartado B, fracción XIII, de la Constitución Política de los Estados Unidos Mexicanos, los agentes de la Policía Federal Ministerial son empleados públicos nombrados mediante actos condición, los cuales se encuentran excluidos de los derechos laborales consagrados en favor de los trabajadores al servicio del Estado, entre ellos, los de estabilidad en el empleo e inmutabilidad de toda condición de ingreso o permanencia en el cargo, en virtud de las características particulares del servicio encomendado. Por lo anterior, si en el juicio de amparo aquéllos solicitan la suspensión de los efectos y consecuencias de los actos dentro del procedimiento de separación del servicio de carrera de procuración de justicia federal, bajo el argumento de que, en caso de dictarse la resolución respectiva, no se les reinstalaría en el puesto que desempeñan, tal aspecto resulta insuficiente para considerar que se está en presencia de actos de difícil reparación, pues tales actuaciones no quebrantan de manera cierta e inmediata algún derecho sustantivo protegido por las garantías individuales, ya que su actualización sólo produce efectos formales, por ser meramente procesales, además de que la propia Constitución Federal establece la forma de resarcir al afectado mediante indemnización. Por tanto, al no estar en presencia de actos que tengan sobre las personas o las cosas una ejecución de difícil reparación, es improcedente conceder la medida cautelar solicitada, al no satisfacerse el requisito previsto en la fracción III del artículo 124 de la Ley de Amparo.

\section{SÉPTIMO TRIBUNAL COLEGIADO EN MATERIA ADMINISTRATIVA DEL} PRIMER CIRCUITO.

Queja 58/2011. Director General de Asuntos Jurídicos de la Procuraduría General de la República en representación del titular de la Agencia Federal de Investigación, del titular del Centro de Evaluación y Control de Confianza y de la Secretaría Instructora del Órgano Auxiliar de Instrucción del Consejo de Profesionalización, todos de la mencionada Procuraduría. 6 de mayo de 2011. Unanimidad de votos. Ponente: Alberto Pérez Dayán. Secretaria: Martha Izalia Miranda Arbona.

Queja 138/2011. Secretaría Instructora del Órgano Auxiliar de Instrucción del Consejo de Profesionalización de la Procuraduría General de la República. 13 de diciembre de 2011. Unanimidad de votos. Ponente: Adela Domínguez Salazar. Secretaria: Aurora del Carmen Muñoz García. 


\begin{tabular}{|l|l|l|l|}
\hline TesisXVI.1o.A.T.17 K & $\begin{array}{l}\text { Semanario Judicial } \\
\text { de la Federación y } \\
\text { su Gaceta }\end{array}$ & $\begin{array}{l}\text { Novena } \\
\text { Época }\end{array}$ & 1617328 de 198 \\
\hline $\begin{array}{l}\text { PRIMER TRIBUNAL } \\
\text { COLEGIADO EN MATERIAS } \\
\begin{array}{l}\text { ADMINISTRATIVA Y DE } \\
\text { TRABAJO DEL DÉCIMO SEXTO } \\
\text { CIRCUITO. }\end{array}\end{array}$ & $\begin{array}{l}\text { XXXIII, Junio de } \\
2011\end{array}$ & $\begin{array}{l}\text { Pág. } \\
1600\end{array}$ & $\begin{array}{l}\text { Tesis } \\
\text { Aislada(Común) }\end{array}$ \\
\hline
\end{tabular}

[TA]; 9a. Época; T.G.C.; S.J.F. y su Gaceta; XXXIII, Junio de 2011; Pág. 1600

SUSPENSIÓN PROVISIONAL. ES IMPROCEDENTE CONCEDERLA CONTRA LA DETERMINACIÓN DE SEPARAR TEMPORALMENTE DEL CARGO A UN AGENTE DEL MINISTERIO PÚBLICO DE LA FEDERACIÓN POR NO APROBAR LOS PROCESOS DE EVALUACIÓN DE CONTROL DE CONFIANZA, DADO QUE CON SU OTORGAMIENTO SE AFECTARÍA EL INTERÉS SOCIAL Y SE CONTRAVENDRÍAN DISPOSICIONES DE ORDEN PÚBLICO.

Por mandato de los artículos 21 y 102, apartado A, de la Constitución Política de los Estados Unidos Mexicanos y 4o., fracción v, de la abrogada Ley Orgánica de la Procuraduría General de la República, el Ministerio Público de la Federación realiza funciones de interés público y general, al promover la pronta, expedita y debida procuración e impartición de justicia. Por su parte, el artículo 123, apartado B, fracción XIII, segundo párrafo, de la Carta Magna dispone que los agentes del Ministerio Públicos podrán ser separados de sus cargos si no cumplen con los requisitos que las leyes vigentes en el momento del acto señalen para permanecer en aquéllos y que si la autoridad jurisdiccional resolviere que la separación fue injustificada, el Estado sólo estará obligado a pagar la indemnización y demás prestaciones a que tenga derecho, sin que en ningún caso proceda su reincorporación al servicio, cualquiera que sea el resultado del juicio o medio de defensa que se hubiere promovido. Así, las anteriores disposiciones constitucionales reflejan la preocupación del Poder Revisor de la Constitución y del legislador por salvaguardar el correcto ejercicio de la función de la representación social, de modo que únicamente pueda llevarse a cabo por personas sobre las que no exista dejo de duda con relación a que cumplen cabalmente los requisitos respecto a su ingreso y permanencia dentro de la mencionada procuraduría, dada la trascendencia de la función que tienen encomendada. En estas condiciones, los artículos 30, fracción I, inciso b) y 31 , fracción II, inciso b), de la citada ley orgánica disponen como requisitos para permanecer como agente del Ministerio Público de la Federación de carrera, entre otros, el sometimiento y aprobación de los procesos de evaluación de control de confianza y del desempeño, los que serán permanentes, periódicos y obligatorios. Por tanto, es improcedente conceder la suspensión provisional contra la determinación que separa provisionalmente del cargo a un agente del Ministerio Público de la Federación por no aprobar los referidos procesos de evaluación, en razón de que con su otorgamiento se afectaría el interés social y se contravendrían disposiciones de orden público conforme al artículo $\underline{124}$, fracción II, de la Ley de Amparo, pues la sociedad está interesada en que las funciones del Ministerio Público se realicen de la mejor manera.

PRIMER TRIBUNAL COLEGIADO EN MATERIAS ADMINISTRATIVA Y DE TRABAJO DEL DÉGIMO SEXTO CIRCUITO.

Queja 10/2011. Agente del Ministerio Público de la Federación adscrito al Juzgado Tercero de Distrito en el Estado de Guanajuato. 10 de marzo de 2011. Unanimidad de votos. Ponente: Ariel Alberto Rojas Caballero. Secretaria: Silvia Vidal Vidal.

Nota: Esta tesis es objeto de la denuncia relativa a la contradicción de tesis 137/2012, pendiente de resolverse. 


\begin{tabular}{|l|l|l|l|}
\hline TesisII.4o.A.34 A & $\begin{array}{l}\text { Semanario } \\
\text { Judicial de la } \\
\text { Federación y su } \\
\text { Gaceta }\end{array}$ & $\begin{array}{l}\text { Novena } \\
\text { Época }\end{array}$ & 16212213 de 198 \\
\hline $\begin{array}{l}\text { CUARTO TRIBUNAL } \\
\text { COLEGIADO EN MATERIA } \\
\begin{array}{l}\text { ADMINISTRATIVA DEL } \\
\text { SEGUNDO CIRCUITO. }\end{array}\end{array}$ & $\begin{array}{l}\text { XXXIII, Mayo } \\
\text { de } 2011\end{array}$ & Pág. 1192 & $\begin{array}{l}\text { Tesis } \\
\text { Aislada(Administrativa) }\end{array}$ \\
\hline
\end{tabular}

[TA]; 9a. Época; T.C.C.; S.J.F. y su Gaceta; XXXIII, Mayo de 2011; Pág. 1192

INDEMNIZACIÓNDELOSMIEMBROSDE LASCORPORACIONESPOLICLALESDELESTADO DE MÉXICO CON MOTIVO DE LA REMOCIÓN DE SU CARGO. SU CUANTIFICACIÓN $Y$ LA DE LAS DEMÁS PRESTACIONES A QUE TIENEN DERECHO DEBE REALIZARSE CONFORME A LOS PARÁMETROS ESTABLECIDOS EN LOS ARTÍCULOS 49 Y 50 DE LA LEY FEDERAL DEL TRABAFO.

El artículo 123, apartado B, fracción XIII, de la Constitución Política de los Estados Unidos Mexicanos, reformado mediante decreto publicado en el Diario Oficial de la Federación el 18 de junio de 2008, dispone que cuando resulte injustificada la separación del servicio de los miembros de las instituciones policiales de los Estados y Municipios, el Estado sólo estará obligado a pagar la indemnización y demás prestaciones a que tengan derecho, sin que la citada Norma Fundamental establezca lineamientos para ese efecto, por lo que tal aspecto corresponde regularlo a las leyes secundarias. Por su parte, el artículo 193 de la Ley de Seguridad Pública Preventiva del Estado de México, únicamente dispone que los miembros de la Agencia de Seguridad Estatal que componen el Cuerpo de Seguridad Pública Estatal, podrán ser removidos de su cargo y funciones cuando incurran en alguna de las causales que establece el artículo 78 de la propia legislación, o bien, por no reunir los requisitos de ingreso y permanencia, y que cualquiera que sea el medio de defensa por el que se impugne la remoción, no será procedente la restitución o reinstalación, sino sólo la indemnización, de conformidad con el referido precepto constitucional, lo cual genera incertidumbre jurídica. Por tanto, con la finalidad de dotar de eficacia al indicado artículo 123, y de generar una labor integradora en su contenido, se concluye que la cuantificación de la indemnización y demás prestaciones a que tienen derecho los miembros de las corporaciones policiales de la mencionada entidad federativa que hayan sido removidos de su cargo, debe realizarse conforme a los parámetros establecidos en los artículos 49 y 50 de la Ley Federal del Trabajo, sin que lo anterior pugne o cuestione la relación que existe entre los cuerpos de seguridad pública y el Estado de México, la cual es eminentemente administrativa, pues no aceptar dicha remisión implica una consecuencia más gravosa para el régimen jurídico interno, consistente en la ineficacia de una norma constitucional.

GUARTO TRIBUNAL COLEGIADO EN MATERIA ADMINISTRATIVA DEL SEGUNDO CIRCUITO.

Amparo directo 461/2010. Ramiro Bolaños Cruz. 11 de noviembre de 2010. Unanimidad de votos. Ponente: Adalberto Eduardo Herrera González. Secretario: Erik Juárez Olvera.

Nota: Sobre el tema tratado, la Segunda Sala resolvió la contradicción de tesis $61 / 2011$, de la que derivó la tesis jurisprudencial 2a./J. 119/2011 de rubro: "SEGURIDAD PÚBLICA. PARA DETERMINAR LOS GONCEPTOS QUE DEBEN INTEGRAR LA INDEMNIZAGIÓN ESTABLEGIDA EN EL ARTÍCULO 123, APARTADO B, FRAGGIÓN XIII, DE LA GONSTITUCIÓN POLÍTICA DE LOS ESTADOS UNIDOS MEXICANOS, NO ES APLICABLE, NI AUN SUPLETORIAMENTE, LA LEY FEDERAL DEL TRABAJO." 


\begin{tabular}{|l|l|l|l|}
\hline TesisIV.3o.A.134 A & $\begin{array}{l}\text { Semanario } \\
\text { Judicial de la } \\
\text { Federación y su } \\
\text { Gaceta }\end{array}$ & $\begin{array}{l}\text { Novena } \\
\text { Época }\end{array}$ & 16261314 de 198 \\
\hline $\begin{array}{l}\text { TERCER TRIBUNAL } \\
\text { COLEGIADO EN MATERIA } \\
\begin{array}{l}\text { ADMINISTRATIVA DEL } \\
\text { CUARTO CIRCUITO. }\end{array}\end{array}$ & $\begin{array}{l}\text { XXXIII, Marzo } \\
\text { de } 2011\end{array}$ & Pág. 2299 & Tesis Aislada(Común) \\
\hline
\end{tabular}

[TA]; 9a. Época; T.C.C.; S.J.F. y su Gaceta; XXXIII, Marzo de 2011; Pág. 2299

CUERPOS DE SEGURIDAD PÚBLICA. LA CONCESIÓN DEL AMPARO CONTRA LA SEPARACIÓN EN EL CARGO DE SUS MIEMBROS NO PUEDE SER PARA EL EFECTO DE QUE SEAN REINSTALADOS, AUN CUANDO EL ACTO RECLAMADO HAYA SIDO DICTADO POR AUTORIDAD INCOMPETENTE.

Acorde con la jurisprudencia 2a./J. 103/2010 de la Segunda Sala de la Suprema Corte de Justicia de la Nación, publicada en el Semanario Judicial de la Federación y su Gaceta, Novena Época, Tomo XXXII, julio de 2010, página 310, de rubro: "SEGURIDAD PÚBLICA. LA PROHIBICIÓN DE REINSTALAR EN SU CARGO A LOS MIEMBROS DE LAS INSTITUCIONES POLICIALES, PREVISTA POR EL ARTÍCULO 123, APARTADO B, FRACGIÓN XIII, DE LA CONSTITUCIÓN GENERAL DE LA REPÚBLICA, REFORMADO MEDIANTE DECRETO PUBLICADO EN EL DIARIO OFICIAL DE LA FEDERACIÓN EL 18 DE JUNIO DE 2008, ES APLICABLE EN TODOS LOS CASOS, INDEPENDIENTEMENTE DE LA RAZÓN QUE MOTIVÓ EL CESE.”, los miembros de las instituciones de seguridad pública podrán ser separados de sus cargos si no cumplen con los requisitos de permanencia o incurren en responsabilidad y, en caso de que la autoridad resolviere que la separación fue injustificada, el Estado sólo está obligado a pagar la indemnización y demás prestaciones a que tengan derecho, sin que en ningún caso proceda su reincorporación, cualquiera que sea el resultado del juicio o medio de defensa promovido. Así, en términos de los mencionados lineamientos, la prohibición de la reinstalación es absoluta. Por tanto, la concesión del amparo contra la separación en el cargo de los miembros de los cuerpos de seguridad pública no puede ser para el efecto de que sean reinstalados, aun cuando el acto reclamado haya sido dictado por autoridad incompetente, supuesto en el que la protección de la Justicia Federal será, en todo caso, para el efecto de que les sean pagadas la indemnización y demás prestaciones a que tengan derecho.

\section{TERCER TRIBUNAL COLEGIADO EN MATERIA ADMINISTRATIVA DEL GUARTO CIRCUITO.}

Amparo en revisión 181/2010. Christian Morales Álvarez. 19 de agosto de 2010. Unanimidad de votos. Ponente: Jesús R. Sandoval Pinzón. Secretario: Pedro Gerardo Álvarez Álvarez del Castillo.

Amparo directo 207/2010. Noé Hernández Reyhlander. 26 de agosto de 2010. Unanimidad de votos. Ponente: Jesús R. Sandoval Pinzón. Secretario: Pedro Gerardo Álvarez Álvarez del Castillo.

Nota: Esta tesis es objeto de la denuncia relativa a la contradicción de tesis 51/2012, pendiente de resolverse por la Segunda Sala. 


\section{CONSIDERACIONES FINALES}

La Reforma Constitucional Penal en México del 18 de junio de 2008, implica la modificación de 10 artículos Constitucionales, y son a saber: 16, 17, 18, 19, 20, 21, 22, 73 fracciones XXI, y XXIII, 115 fracción VII y fracción XIII del apartado B del artículo 123 de la Constitución Política de los Estados Unidos Mexicanos vigente, representa una ruptura epistemológica para con el Sistema Penal Inquisitorio Mixto, eminentemente formalista. El cual, es sustituido por el paradigma del garantismo que subyace en el Sistema Penal Acusatorio Adversarial, que además, se vincula con la corriente del realismo jurídico contemporáneo.

Así pues, de la lectura y análisis que se haga del contenido textual del artículo 20 de la Constitución Política de los Estados Unidos Mexicanos vigente, identificamos que en el artículo antes mencionado, en el apartado $\mathrm{A}$, con $\mathrm{x}$ fracciones, se establecen los principios generales del sistema penal acusatorio adversarial-vía los juicios orales. En su apartado B, con sus IX fracciones, se regulan los derechos de toda persona imputada y en el apartado c, con VII fracciones, se mencionan los derechos de la víctima o del ofendido. Habida cuenta a lo antes expresado, se desprenden los lineamientos teóricos y metodológicos que esquematizan al sistema penal acusatorio, de naturaleza garantista, respetuoso de la dignidad humana, y demás derechos fundamentales tanto del acusador como del acusado. Además, se distingue por garantizar el principio de presunción de inocencia, del debido proceso legal, la seguridad y certeza jurídica, la objetividad, transparencia e imparcialidad en la impartición de justicia. Las características antes mencionadas son acordes a un Estado de Derecho Social Democrático.

Ahora bien, el tema central de la presente investigación versa acerca del último párrafo de la Fracción XIII del apartado B del artículo 123 de la Constitución Política de los Estados Unidos Mexicanos vigente, y que a la letra expresa lo siguiente:

Artículo 123. Toda persona tiene derecho al trabajo digno y socialmente útil; al efecto, se promoverán la creación de empleos y la organización social de trabajo, conforme a la ley.

Apartado B...

XIII. Los militares, marinos, personal del servicio exterior, agentes del Ministerio Público, peritos y los miembros de las instituciones policiales, se regirán por sus propias leyes.

Los agentes del Ministerio Público, los peritos y los miembros de las instituciones policiales de la Federación, el Distrito Federal, los Estados y los Municipios, podrán ser separados de sus cargos si no cumplen con los requisitos que las leyes vigentes en el momento del acto señalen para permanecer en dichas instituciones, 
o removidos por incurrir en responsabilidad en el desempeño de sus funciones. Si la autoridad jurisdiccional resolviere que la separación, remoción, baja, cese o cualquier otra forma de terminación del servicio fue injustificada, el Estado sólo estará obligado a pagar la indemnización y demás prestaciones a que tenga derecho el servidor público, sin que en ningún caso proceda su reincorporación al servicio, cualquiera que sea el resultado del juicio o medio de defensa que se hubiere promovido. $^{33}$

Del análisis gramatical, lógico jurídico del referido párrafo se advierte una clara incongruencia de quienes participaron en la Reforma Constitucional Penal del 18 de junio de 2008. Es decir, dicha reforma se le identifica por su sustento garantista al reiterar el principio de presunción de inocencia, el debido proceso legal, seguridad y certeza jurídica.

Sin embargo, de la lectura del referido párrafo se desprende una contradicción manifiesta al expresar de manera tan ambigua que el servidor público que resulte inocente será suspendido de sus funciones y no podrá ser reinstalado en el desempeño de sus funciones, y sólo tendrá derecho a una indemnización.

Consecuentemente, con el propósito de identificar por una parte, el marco normativo jurídico del garantismo que sustenta a la Reforma Constitucional Penal del 18 de junio de 2008, y de la Reforma Constitucional del 10 de junio de 2011 , a través de los siguientes artículos: $1^{\circ}, 5^{\circ}, 14^{\circ}, 16^{\circ}$, $17^{\circ}, 20^{\circ}$ y $123^{\circ}$. Lo cual, nos permite precisar las antinomias o contradicciones que fundamentan lo referente al último párrafo de la fracción XIII del apartado B del artículo 123 Constitucional. En dicho párrafo al negarse la reinstalación del servidor público cuando resulta inocente se rompe el esquema garantista, y por lo consiguiente, se llega a una clara expresión intolerante, autoritaria y fascista ${ }^{34}$, y por la otra, parte, con la existencia de los preceptos normativos que se encuentran tanto en la Declaración Universal de los derechos Humanos, como de las Convenciones Internacionales se esquematiza el fundamento jurídico internacional, que nos permite ahondar en razones jurídico políticas y éticas en contra de las expresiones auto-

\footnotetext{
${ }^{33}$ Cámara de Diputados: Reformas a la Constitución; Reformas Constitucionales en Orden Cronológico, Reforma Penal Constitucional de 18 de junio de 2008. Fuente de consulta: http://www.diputados. gob.mx/LeyesBiblio/ref/dof/cPEum ref_180_18jun08.pdf. Fecha de consulta: 18 de mayo de 2012.

${ }^{34}$ En psicosociología, la palabra fascismo (y su letra inicial "F") ha sido utilizada para designar una escala que pretende mediar la existencia de un tipo de personalidad caracterizada por el convencionalismo, la sumisión de tipo autoritario, la agresión de estilo autoritario, la oposición a los sujetos imaginativos, sensitivos, la superstición y la estereotipia, la preocupación por el poder y la tenacidad, la tendencia a la destrucción y el cinismo... Hay una interpretación que considera al fascismo italiano como una aberración pasajera, al modo de otras tantas tiranías fugaces que ha padecido Italia en su historia. (Fuenzalida Faivovich, E.: "Fascismo", concepto publicado en el Diccionario unesco de Ciencias Sociales. Ed. Planeta-De Agostini, s.A., Barcelona-España, noviembre 1987. Vol. II. pp. 869 y 870.
} 
ritarias que impactan al paradigma garantista que hoy en día cuestionan las arbitrariedades que se cometen al violar los derechos fundamentales que se consagran en un Estado de Derecho Social Democrático.

Habida cuenta lo antes expresado, y con el propósito fundamental de corregir la aberración jurídica antes mencionada, se propone una reforma de adición al último párrafo de la fracción XIII del apartado B del artículo 123 constitucional en los siguientes términos:

Artículo 123. Toda persona tiene derecho al trabajo digno y socialmente útil; al efecto, se promoverán la creación de empleos y la organización social de trabajo, conforme a la ley.

Apartado B...

XIII... Los militares, marinos, personal del servicio exterior, agentes del Ministerio Público, peritos...

Los agentes del Ministerio Público, los peritos y los miembros de las instituciones policiales de la Federación...

Si la autoridad jurisdiccional resolviere que la separación, remoción, baja, cese o cualquier otra forma de terminación del servicio fue injustificada, de acuerdo al resultado del juicio o medio defensa que se hubiere promovido, el Estado se obliga a reincorporar al servidor público al servicio de su cargo que venía ocupando, o a pagar la indemnización y demás prestaciones a que tenga derecho el servidor público.

Consecuentemente, la Constitución Política de los Estados Unidos Mexicanos vigente, en diferentes artículos expresa, por una parte, el respeto irrestricto de los derechos fundamentales, entre otros, de libertad, igualdad, seguridad y certeza jurídica, lo cual, obliga a garantizar el respeto y observancia de la dignidad humana y demás derechos fundamentales reconocidos en esta constitución, así como de los tratados y convenciones internacionales.

\section{VI , B I BLIOGRAF ÍA}

Concha Cantú, Hugo Alejandro y José Antonio Caballero Juárez: Diagnóstico sobre la administración de justicia en las entidades federativas. Un estudio institucional sobre la justicia local en México; $1^{\text {a }}$ ed. Ed. Instituto de Investigaciones de Jurídicas de la UnAM, México, D.F. 2001, pp. 317 y 322.

Fuenzalida Faivovich, E.: "Fascismo", concepto publicado en el Diccionario UNESco de Ciencias Sociales. Ed. Planeta - De Agostini, s.A., Barcelona, España, noviembre 1987. Vol. II. pp. 869 y 870.

Guillén, López, Raúl, Cruz Covarrubias, Armando E.; Guillén, López, Raúl, Cruz Covarrubias, Armando E.: La justicia penal en México. Un estudio de caso; $1^{\mathrm{a}}$ ed. Ed. Instituto de Investigaciones Jurídicas de la UnAM, México, D.F. 2008, p. 84 . 
Kaplan, Marcos: Del Derecho y del Jurista; art. publ. en el periódico El Financiero, sección cultural "Biblioteca". México, D.F., viernes 3 de Diciembre de 1993, p. 15.

Natarén Nandayapa, Carlos F.: Breves Reflexiones sobre algunos de los retos en el diseño del nuevo proceso penal ordinario; artículo publicado en el libro: García Ramírez, Sergio y de González Mariscal, Olga Islas (Coordinadores): La Reforma Constitucional en Materia Penal Jornadas de Justicia Penal; Coedición de: IJJ-UnAm e INACiPE, México, D.F., 2009. p. 229.

Perelman, Ch.; La lógica jurídica y la nueva retórica, trad. al español por Luis DíezPicazo. Ed. Civitas, Madrid, 1979, p. 231.

Pineda, Fanny: Responsabilidad del Estado; artículo publicado en: Diccionario Jurídico Mexicano, Rep-z; Tomo VIII, en coedición por el Instituto de Investigaciones Jurídicas de la UnAm y Porrúa, México, 1984. pp. 47 y 48.

Quiroz Cuarón, Alfonso, "Crisis de la administración de justicia penal”, Revista de la Facultad de Derecho de México, núms. 41-42, enero-junio de 1961, pp. 319-348. Cit. por Zepeda Lecuona, Guillermo R.: "Notas para un diagnostico de la procuración de justicia en el fuero común”, art. publ. en Sergio García Ramírez: Liber ad Honorem. $1^{\text {a }}$ ed. Tomo II. Ed. Instituto de Investigaciones Jurídicas-Unam. México, D.F. 1998. p. 1547.

Roemer, Andrés: Economía del crimen; $1^{\text {a }}$ ed. Ed. Limusa, S.A. de G.V. México, D.F. 2001. p. 235.

Sánchez Gómez, Narciso: Primer curso de Derecho Administrativo; $1^{\mathrm{a}}$ ed. 1998, $4^{\mathrm{a}}$ ed. Ed. Porrúa, S.A. de C.V. México, D.F. 2005, p. 424.

Sánchez Vázquez, Rafael: Metodología de la Ciencia del Derecho; $8^{\mathrm{a}}$ ed. (agotada) Ed. Porrúa, s.A. México, D.F. 2008, pp. 219-252.

Serra Rojas, Andrés: Derecho Administrativo. Doctrina, Legislación y Jurisprudencia, primer curso; $1^{\mathrm{a}}$ ed. 1959, $23^{\mathrm{a}}$ corregida y aumentada por Andrés Serra Rojas Beltri, Ed. Porrúa, s.A. de c.v. México, D.F. 2002. p. 501.

Soberanes Fernández, José Luis: Responsabilidades de los servidores públicos; artículo publicado en: Diccionario Jurídico Mexicano, Rep-z; Tomo vIII, en coedición por el Instituto de Investigaciones Jurídicas de la UnAM y Porrúa, México, 1984. p. 52.

Tamayo y Salmoran, Rolando: Responsabilidad; artículo publicado en: Diccionario Jurídico Mexicano, Rep-z; Tomo viII, en coedición por el Instituto de Investigaciones Jurídicas de la unam y Porrúa, México, 1984. pp. 14 y 15.

\section{DIRECCIONES ELECTRÓNICAS}

Cámara de Diputados: Poder Legislativo, Lx Legislatura, Diario de los Debates, Primer Periodo de Sesiones Ordinarias del Segundo Año de Ejercicio, Diario No. 35, miércoles 12 de diciembre de 2007.

http://cronica.diputados.gob.mx. Fecha de consulta 25 de mayo de 2012.

Cámara de Diputados: Reformas a la Constitución; Reformas Constitucionales en Orden Cronológico, Reforma Penal Constitucional de 18 de junio de 2008. Fuente de consulta:

http://www.diputados.gob.mx/LeyesBiblio/ref/dof/CPEuM_ref_180_18jun08.pdf. Fecha de consulta: 18 de mayo de 2012. 
Cámara de Senadores: Poder Legislativo, Lx Legislatura, Diario de los Debates, primer Periodo de Ordinario de Sesiones del Segundo Año de Ejercicio, Diario No. 34, 13 de diciembre de 2007. Fuente de Consulta:

http://www.senado.gob.mx/index.php?ver=sp\&mn=3\&sm=3\&lg=LX_II\&id=759

Datos de la encuesta victimológica realizada por el Instituto de Estudios Ciudadanos sobre la Inseguridad (ICESI). La encuesta ENSI-3 se realizó del 15 de febrero al 15 de marzo de 2005, con información sobre el historial de victimización para todo el año 2004, con una muestra total de 66,000 cuestionarios aplicados en viviendas de las 32 entidades federativas de la República Mexicana. Cit. por Vizcaíno Zamora, Álvaro: La Formación de Agentes del Ministerio Público en Francia y México; artículo publicado por el INACIPE.

ht t p: / / www.inacipe.gob.mx/index.php? option = com _ content\&view $=$ article $\& i d=376: 1 a-$ formacion-de-agentes-delministerio-publico-en-francia-y-mexico-autor-alvaro-vizcainozamora\&catid=37:alvaro-vizcaino-zamora \&Itemid $=171$. Fecha de consulta: 26 de mayo de 2012.

http:/ / www.senado.gob.mx/index.php?ver $=$ sp $\& m n=3 \& s m=3 \& \lg =\mathrm{LX}$ II\&id=759. Fecha de consulta 25 de junio de 2012.

Índices creados por Guillermo Zepeda. Disponible en www.cidac.org Madrazo Cuéllar, Jorge: Las reformas constituciones en materia penal; http://www.juridicas.unam.mx/publica/rev/cconst/cont/1/cl/cll1.htm. Fecha de consulta 20 de junio de 2012.

Reforma 24 de abril de 1998. Citado en siss: Sistema de Índices e Indicadores en Seguridad Pública. http://www.mexicoevalua.org/descargables/5ela0a_sistema_de_indices-e-indicadores_en_seguridad_publica_completo_impresion_nov19.pdf. Fecha de consulta: 26 de mayo de 2012. 